\title{
Emergence delirium is associated with increased postoperative delirium in elderly: a prospective observational study
}

\author{
Yan Zhang ${ }^{1} \cdot$ Shu-Ting $\mathrm{He}^{1} \cdot$ Bin Nie $^{2} \cdot$ Xue-Ying $\mathrm{Li}^{3} \cdot$ Dong-Xin Wang ${ }^{1,4}$
}

Received: 1 March 2020 / Accepted: 30 May 2020 / Published online: 7 June 2020

(c) The Author(s) 2020

\begin{abstract}
Background The clinical significance of emergence delirium remains unclear. The purpose of this study was to investigate the association between emergence delirium and postoperative delirium in elderly after general anesthesia and surgery.

Methods This prospective observational study was done in a tertiary hospital in Beijing, China. Elderly patients (6590 years) who underwent major noncardiac surgery under general anesthesia and admitted to the postanesthesia care unit (PACU) after surgery were enrolled. Emergence delirium was assessed with the Confusion Assessment Method for the Intensive Care Unit during PACU stay. Postoperative delirium was assessed with the Confusion Assessment Method during the first 5 postoperative days. The association between emergence delirium and postoperative delirium was analyzed with a multivariable logistic regression model.

Results A total of 942 patients were enrolled and 915 completed the study. Emergence delirium developed in 37.0\% (339/915) of patients during PACU stay; and postoperative delirium developed in 11.4\% (104/915) of patients within the first 5 postoperative days. After adjusted confounding factors, the occurrence of emergence delirium is independently associated with an increased risk of postoperative delirium (OR 1.717, 95\% CI 1.078-2.735, $P=0.023$ ). Patients with emergence delirium stayed longer in PACU and hospital after surgery, and developed more non-delirium complications within 30 days.

Conclusions Emergence delirium in elderly admitted to the PACU after general anesthesia and major surgery is independently associated with an increased risk of postoperative delirium. Patients with emergence delirium had worse perioperative outcomes.
\end{abstract}

Chinese Clinical Trial Registry (chictr.org.cn) ChiCTR-OOC-17012734

Keywords Elderly $\cdot$ General anesthesia $\cdot$ Major surgery $\cdot$ Emergence delirium $\cdot$ Postoperative delirium

Yan Zhang and Shu-Ting He contributed equally to this work

Electronic supplementary material The online version of this article (https://doi.org/10.1007/s00540-020-02805-8) contains supplementary material, which is available to authorized users.

Dong-Xin Wang

wangdongxin@hotmail.com; dxwang65@bjmu.edu.cn

1 Departments of Anesthesiology and Critical Care Medicine, Peking University First Hospital, No.8 Xishiku Street, Beijing 100034, China

2 Departments of Anesthesiology, Fujian Provincial Cancer Hospital, Fuzhou, Fujian, China

3 Department of Biostatistics, Peking University First Hospital, Beijing, China

4 Department of Outcomes Research Consortium, Cleveland Clinic, Cleveland, OH, USA

\section{Introduction}

Delirium is a common complication in elderly patients after surgery [1]. According to the onset time, delirium in the postoperative period can be classified as emergence delirium and postoperative delirium (POD). Emergence delirium occurs during or immediately after emergence from general anesthesia; whereas POD is usually notable from postoperative day 1 and up to 1 week after surgery $[2,3]$. The reported incidence of the two types of delirium varies depending on patient population, type of anesthesia/surgery, and assessment methods. Indeed, emergence delirium occurs in $3.7-45 \%$ of patients [4-15] and the reported rate of POD is $5-54 \%$ after noncardiac surgeries [16-18].

The underlying mechanisms of POD remain unclear but multi-risk factors include predisposing and precipitating factors are associated with its development [1]. The 
development of POD is associated with worse outcomes such as more complications, longer hospital stays, higher medical expense, as well as shortened overall survival and lowered quality of life [19-21]. In contrast, it was considered that emergence delirium is likely related to the effects of residual general anesthetics and is "self-limited" without sequelae [2, 4]. However, recent studies suggested that emergence delirium shares some common risk factors with POD, and that its occurrence is also associated with worse perioperative outcomes including more pulmonary complications, longer length of hospital stay and high readmission rate $[5,8-10,14,15,22]$.

Studies of emergence delirium in the elderly are inadequate and the clinical significance of emergence delirium remains poorly understood. We hypothesize that elderly with emergence delirium would have a higher risk of postoperative delirium and worse outcomes. The primary purpose of this study was to investigate the association between emergence delirium and POD in elderly after general anesthesia and major surgery.

\section{Methods}

\section{Study design}

This prospective observational study was carried out in a tertiary hospital in Beijing, China. The study protocol was approved by the Clinical Research Ethics Committee of Peking University First Hospital on August 4, 2017 (2017[1419], Beijing, China) and was registered with Chinese Clinical Trial Registry on September 19, 2017 (chictr. org.cn, ChiCTR-OOC-17012734). Written informed consent was obtained from all participants or their legal representatives.

\section{Participants}

The inclusion criteria were patients aged 65-90 years who were scheduled to undergo major noncardiac surgery with an expected duration $\geq 2 \mathrm{~h}$ under general anesthesia and admitted to the post-anesthesia care unit (PACU) after surgery. Patients who met any of the following criteria were excluded: (1) refused to participate in the study; (2) previous history of schizophrenia, epilepsy, Parkinson's Disease, or myasthenia gravis; (3) unable to communicate due to severe dementia, comatose or language barrier; (4) traumatic brain injury or neurosurgery; or (5) an American Society of Anesthesiologists (ASA) classification of IV or above.

\section{Anesthesia and perioperative care}

Monitoring in the operating room includes electrocardiogram, non-invasive blood pressure, pulse oxygen saturation, end-tidal carbon dioxide, expired concentration of inhalational anesthetics, bispectral index, and urine output. Invasive arterial pressure and central venous pressure were monitored when considered necessary. General anesthesia was induced with propofol and/or etomidate, opioids (sufentanil and/or remifentanil) and muscle relaxants (rocuronium or cisatracurium). Airway was secured with a laryngeal mask or an endotracheal tube, depending on the type and estimated length of surgery as well as patients' position during surgery. Anesthesia was maintained with propofol infusion and/or sevoflurane inhalation, with or without nitrous oxide. Opioids and muscle relaxants were administered when considered necessary. Nonsteroidal anti-inflammatory drugs were administered for those without contraindications at the discretion of anesthesiologists. The target was to maintain bispectral index between 40 and 60 .

Before the end of surgery, muscle relaxants were stopped for at least $30 \mathrm{~min}$; propofol infusion and/or sevoflurane inhalation were decreased or stopped according to BIS monitoring; sufentanil was administered when considered necessary. At the end of surgery, residual neuromuscular blockade was reversed with $0.05 \mathrm{mg} / \mathrm{kg}$ neostigmine and $0.02 \mathrm{mg} / \mathrm{kg}$ atropine. Patients were extubated when they met the following criteria: (1) easy to wake up; (2) sufficient reflexes that protect the airway; (3) adequate gas exchange (respiration rate $10-30$ breaths per minute and tidal volume $>6 \mathrm{ml} / \mathrm{kg}$ ); and (4) acceptable hemodynamic status (systolic blood pressure $\geq 90 \mathrm{mmHg}$ and heart rate $\leq 100$ beats per minute). As a routine practice, patients were extubated in the operating room and were transferred to the PACU before being sent back to the wards.

Patients were monitored in PACU for at least $30 \mathrm{~min}$. Routine monitoring included electrocardiogram, noninvasive blood pressure, pulse oxygen saturation. Pain severity was assessed with the numeric rating scale (NRS, an 11 -point scale where $0=$ no pain and $10=$ the worst pain). Moderate to severe pain (NRS pain score $>3$ ) was managed with intravenous opioids and/or non-steroid antiinflammatory drugs (NSAIDs). Tympanic temperature was measured with an infrared ear thermometer. Patients with hypothermia $\left(<36^{\circ} \mathrm{C}\right)$ were managed with warm air blanket. Supplemental oxygen was provided. Patients were transferred to the general ward when they met all of the following criteria: (1) full consciousness; (2) able to lift head for more than $10 \mathrm{~s}$; (3) able to keep airway clear and normal ventilation, pulse oxygen saturation $>95 \%$ in room air for more than $5 \mathrm{~min}$; (4) stable circulation, with heart 
rate and blood pressure within $20 \%$ from baseline without vasoactive drugs; and (5) no anesthesia- or surgery-related complications. In the general wards, patients were monitored intermittently for pulse oxygen saturation and noninvasive blood pressure until next morning.

\section{Data collection and postoperative follow-ups}

Data collection was performed after obtaining written informed consents. Baseline data included demographics, education background, surgical diagnosis, comorbidities, preoperative medication, smoking and alcoholism, Charlson Comorbidity Index [23], laboratory test results, and ASA classification. Baseline cognitive function was evaluated with the Mini-Mental State Examination (MMSE, scores range from 0 to 30 , with higher scores indicating better function) before surgery. Intraoperative data included type of anesthesia, types and doses of anesthetic drugs, intraoperative liquid balance (including estimated blood loss and blood transfusion), type and location of surgery, as well as duration of anesthesia and surgery. Emergence agitation in the operating room was assessed by the attending anesthesiologists using the Richmond Agitation Sedation Scale (RASS; scores range from -5 [unarousable] to +4 [combative] and 0 indicates alert and calm) [24]. A RASS score of $\geq+1$ was defined as having emergence agitation.

Postoperative data during PACU stay included NRS pain score, tympanic temperature, usage of analgesics, occurrence of delirium, occurrence of other adverse events/complications and management, and length of PACU stay. In the general wards, patients were followed up twice daily until the 5th day after surgery for the occurrence of delirium, the severity of pain, usage of analgesics, and the occurrence of other complications.

Prior to the study period, investigators who performed delirium assessment (YZ, STH and BN) were trained to use the Confusion Assessment Method (CAM) [25] and the CAM for the Intensive Care Unit (CAM-ICU) [26] by a psychiatrist (XYS). Both CAM and CAM-ICU detect four features of delirium, i.e., (1) acute onset of mental status changes or a fluctuating course, (2) inattention, (3) disorganized thinking, and (4) altered level of consciousness. To have delirium diagnosed, a patient must display features 1 and 2, with either 3 or $4[25,26]$. The training program included lectures introducing delirium and the CAM/CAM-ICU, as well as simulation courses with patient-actors. The initial training continued until the diagnosis of delirium reached $100 \%$ agreement with the psychiatrist. The training process was repeated at least two times a year. During the study period, investigators who performed delirium assessment did not participate in perioperative care of the enrolled patients. We have used these instruments in our previous studies and have considerable experience with the techniques [27, 28].
In the present study, emergence delirium was defined as delirium that occurred during PACU stay and was assessed with the CAM-ICU at 10 and $30 \mathrm{~min}$ after PACU admission, and before PACU discharge. Immediately before assessing delirium assessment, the level of sedation/agitation was evaluated with the RASS. If the patient was deeply sedated or unarousable ( -4 or -5 on the RASS), delirium assessment was stopped and the patient was noted as comatose. If the RASS was above $-4(-3$ through +5$)$, delirium assessment was performed. Emergence delirium was classified into 3 subtypes, i.e., hyperactive (with a consistently positive RASS, from +1 to +4 ), hypoactive (with a consistently neutral or negative RASS, from 0 to -3 ) and mixed [29]. Postoperative delirium was defined as delirium that occurred in the general wards during postoperative days 1 to 5 and was assessed with the CAM twice daily (8:00-10:00 am, 18:00-20:00 pm). Pain severity was assessed with the NRS at the same time interval as that of delirium.

From the 6th day after surgery, patients were followed up weekly until postoperative day 30 for the occurrence of postoperative complications. For those who were discharged from the hospital, follow-ups were performed by telephone interview. Non-delirium complications were generally defined as any new onset medical conditions that adversely affect patients' recovery and require medical intervention, i.e., grade II or higher on the Clavien-Dindo classification [30,31]. On postoperative day 30, quality of life was evaluated with the World Health Organization Quality of Life-brief version (WHOQOL-BREF, scores range from 0 to 100 , with higher score indicating better quality of life) [32]; cognitive function was evaluated with the Chinese version of Telephone Interview for Cognitive Status-modified (m-TICS, scores range from 0 to 50 , with higher score indicating better cognitive function) [33].

The primary outcome was the occurrence of emergence delirium, i.e., delirium that developed during PACU stay. Secondary outcomes included the incidence of postoperative delirium, the length of PACU and hospital stay after surgery, the occurrence of non-delirium complications within 30 days, and the cognitive function and quality of life in 30-day survivors.

\section{Statistical analysis}

\section{Estimation of sample size}

According to published data and our own results, we assumed that the incidence of emergence delirium and POD was $23.5 \%$ and $8 \%$, respectively. Sample size was estimated with the following formula: 
$n=\frac{Z_{1-\alpha / 2}^{2} V(\hat{\vartheta})}{L^{2}}$

$V\left(\begin{array}{l}\wedge \\ \vartheta\end{array}\right)$ (variance function) is estimated with the sensitivity $(\mathrm{Se}): V\left(\begin{array}{l}\hat{\vartheta} \\ \vartheta\end{array}\right)=S e \times(1-\mathrm{Se})$. L is half-width of confidence interval for clinical acceptance.

With the significance level $(\alpha)$ set at 0.05 , sensitivity $(\mathrm{Se})$ at $80 \%$, and half-width of confidence interval at 0.1 , respectively, a total of 62 cases with positive events was needed. Considering a POD incidence of $8 \%$ and possible drop-out, 942 patients were enrolled in the present study.

\section{Data analysis}

Patients were divided into two groups, i.e., those with emergence delirium and those without. Continuous variables with normal distribution were analyzed with unpaired $t$ test. Continuous variables with non-normal distribution or ordinal data were analyzed with Mann-Whitney U test. Categorical variables were analyzed with Chi squared test, continuity correction Chi squared test or Fisher exact test. Time-toevent results were analyzed using the Kaplan-Meier survival analysis, with the difference between groups tested by the log-rank test. Univariable associations between baseline and perioperative variables and POD were performed with logistic regression analyses. To assess the association between emergence delirium and POD, factors with $P<0.20$ in univariable analyses and those that were considered clinically important were included in a multivariable logistic regression model to adjust the effects of confounding factors. Data analyses were performed with the SPSS 25.0 software (IBM SPSS Inc, Chicago, IL). A two-sided $P<0.05$ was considered statistically significant.

\section{Results}

\section{Patient population}

From September 21, 2017 to April 10, 2019, 942 patients who met the inclusion/exclusion criteria and gave consents and were enrolled into the study. During the study period, 27 patients were excluded due to changed surgical procedures or ICU admission after surgery. At last, 915 patients were included in the final analysis (Fig. 1).

\section{Occurrence of emergence delirium}

Of all included patients, 37.0\% (339/915) developed emergence delirium during PACU stay. The prevalence of

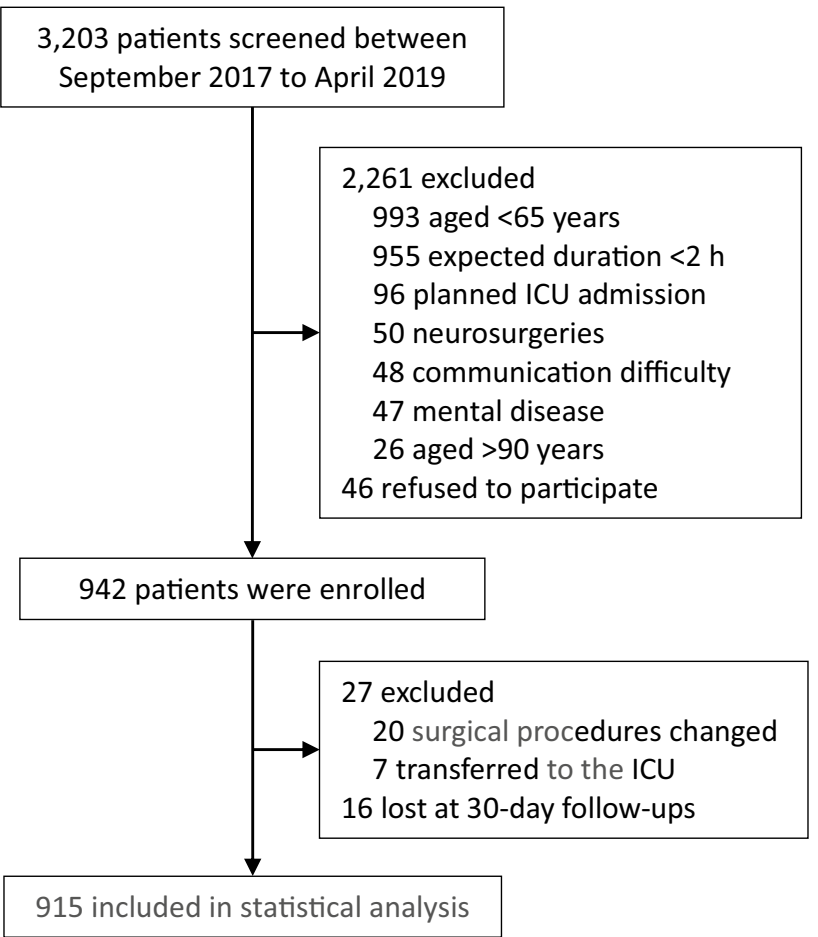

Fig. 1 Flowchart of the study

emergence delirium was the highest at 10 min after PACU admission and gradually decreased along with time; $77.3 \%$ (262/339) of emergence delirium was hypoactive subtype (Fig. 2). Before surgery, patients who developed emergence delirium were older, received shorter education, and had more coronary heart disease, previous surgery and higher ASA grade; but they had lower hematocrit and albumin levels as well as lower MMSE score. During the intra- and postoperative period, patients who developed emergence delirium were given more etomidate and propofol, underwent more non thoraco-/laparoscopic but less intra-thoracic surgeries, lost more blood, received more fluid infusion and blood transfusion, developed more emergence agitation, and had more hypothermia and more severe pain during PACU stay (Table 1).

\section{Effects of emergence delirium on postoperative outcomes}

Of all included patients, 11.4\% (104/915) developed POD within 5 days. The prevalence of POD was the highest in the morning of the first postoperative day, and then gradually decreased along with time (Fig. 3). The incidence of POD was higher in patients with emergence delirium than in those without (16.8\% [57/339] vs. 8.2\% [47/576]; odds ratio [OR] $2.275,95 \%$ CI 1.506-3.436, $P<0.001)$. Regarding other outcomes, patients with emergence delirium stayed longer in PACU, developed more non-delirium complications within 

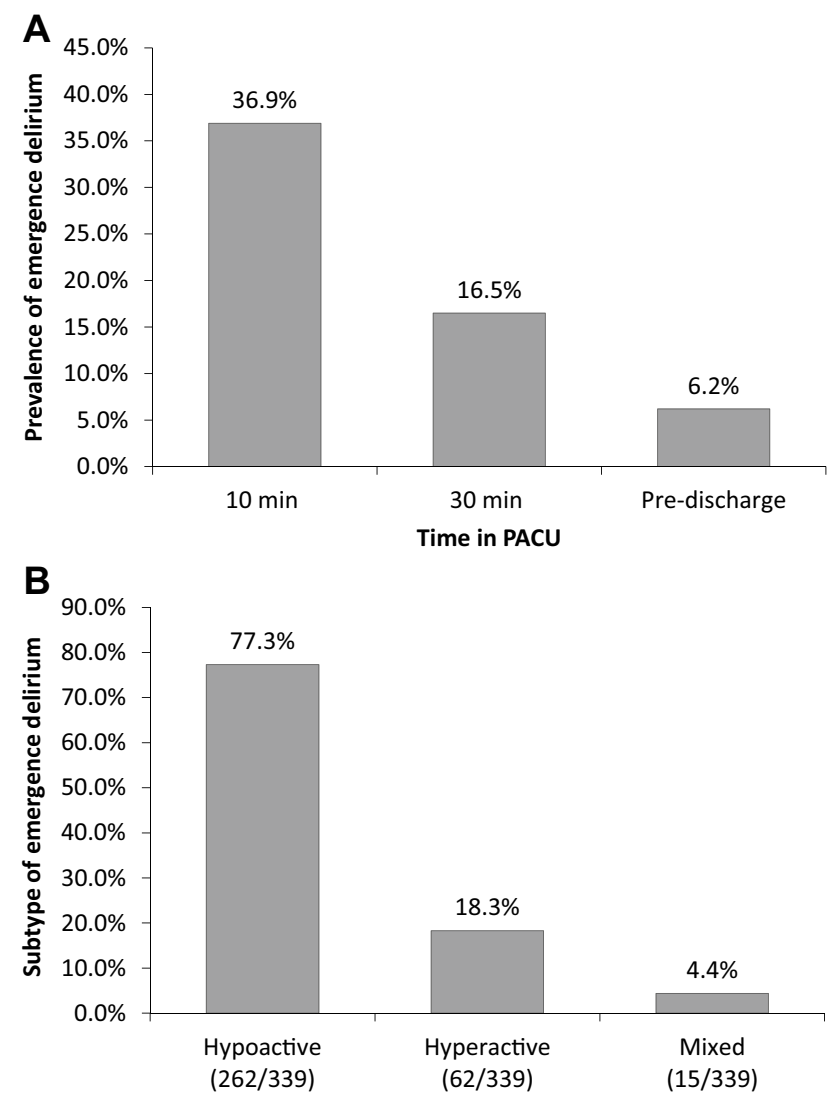

Fig. 2 Prevalence (A) and motoric subtype (B) of emergence delirium after surgery

30 days, and stayed longer in hospital after surgery (Table 2; Supplemental Tables 1 and 2).

\section{Association between emergence delirium and postoperative delirium}

After correction for confounding factors, emergence delirium was independently associated with an increased risk of POD (OR 1.717, 95\% CI 1.078-2.735, $P=0.007$ ) (Table 3 and Table 4).

\section{Risk factors of emergence delirium}

The results showed that advanced age (OR 1.042, 95\% CI $1.003-1.083, P=0.037$ ), occurrence of emergence agitation (OR 6.007, 95\% CI 4.752-7.595, $P<0.001$ ), hypothermia at PACU admission (OR 2.672, 95\% CI 1.790-3.988, $P<0.001$ ), and higher average NRS pain score in PACU (OR 1.309, 95\% CI 1.150-1.489, $P<0.001$ ) were associated with a higher risk; whereas male sex (OR $0.530,95 \%$ CI $0.332-0.846, P=0.008$ ), higher preoperative albumin level (OR 0.953, 95\% CI 0.912-0.997, $P=0.036$ ) and higher preoperative MMSE score (OR 0.799, 95\% CI 0.727-0.878,
$P<0.001)$ were associated with a lower risk of emergence delirium (Tables 3 and 5).

\section{Discussion}

Our observational study of elderly patients showed that, after general anesthesia and major noncardiac surgery, $37.0 \%$ developed emergence delirium during PACU stay and $11.4 \%$ developed POD. The occurrence of emergence delirium is independently associated with an increased risk of the POD development. Patients with emergence delirium stayed longer in the PACU and hospital after surgery, and developed more non-delirium complications within 30 days.

In the present study, the prevalence of emergence delirium was higher than those reported previously [4-13]. The reasons for this discrepancy may include the followings. Firstly, patients included in the present study were at higher risk. For example, most previous studies included all the types of surgery with any age patients [4-13], whereas our patients were older and underwent longer surgeries. All of which might have increased emergence delirium $[4,5,9$, $12,13]$. Secondly, the delirium assessment methods and timepoints varied in available studies. In fact, some of the previous studies assessed agitation rather than delirium. For example, emergence delirium was defined when the Riker sedation-agitation scale was $\geq 5$ or the RASS was $\geq+1$ or higher $[4,5,7,9,10,13]$. As shown by our results and others, the majority of emergence delirium has a hypoactive phenotype [6]. Thus, those studies might have missed hypoactive delirium and underestimated the incidence. To be noted, emergence delirium often occurs early after anesthesia. When it was assessed at PACU admission in the elderly, the reported prevalence (31-45\%) was similar as ours $[6,14$, 15]. The incidence of POD in our results was well within the range as expected [16-18].

The impact of emergence delirium on the occurrence of POD has not been fully investigated. In an observational study, Xara et al. [5] reported that POD was more common in patients with emergence delirium (defined as a RASS score $\geq+1$ ) or hypoactive emergence (defined as a RASS score $\leq-2$ ). In a recent retrospective case-controlled study, Fields et al. [22] reported that the incidence of POD was significantly higher in patients with emergence agitation (defined as a RASS score $\geq+3$ or required haloperidol). In two small sample size studies of elderly patients, emergence delirium in the PACU was also found to be associated with POD $[14,15]$. In the present study of sufficient sample size, we assessed both emergence delirium and POD according to the consensus published recently [3]. Our results showed that, after adjustment with confounding factors, the occurrence of emergence delirium was independently associated with an increased 
Table 1 Baseline and perioperative data

\begin{tabular}{|c|c|c|c|c|}
\hline & Total $(n=915)$ & Emergence delirium $(n=339)$ & $\begin{array}{l}\text { No emergence delirium } \\
(n=576)\end{array}$ & $P$ value \\
\hline Age (year) & $71.6 \pm 5.2$ & $72.9 \pm 5.7$ & $70.9 \pm 4.8$ & $<0.001$ \\
\hline Male sex & $548(59.9 \%)$ & $192(56.6 \%)$ & $356(61.8 \%)$ & 0.123 \\
\hline Body mass index $\left(\mathrm{kg} / \mathrm{m}^{2}\right)$ & $24.2 \pm 3.5$ & $24.0 \pm 3.7$ & $24.2 \pm 3.3$ & 0.473 \\
\hline Education (year) & $10.2 \pm 4.6$ & $9.4 \pm 4.4$ & $10.6 \pm 4.7$ & $<0.001$ \\
\hline \multicolumn{5}{|l|}{ Preoperative comorbidity } \\
\hline Stroke $^{\mathrm{a}}$ & $52(5.7 \%)$ & $16(4.7 \%)$ & $36(6.3 \%)$ & 0.336 \\
\hline Hypertension & $475(51.9 \%)$ & $173(51 \%)$ & $302(52.4 \%)$ & 0.683 \\
\hline Coronary heart disease & $129(14.1 \%)$ & $58(17.1 \%)$ & $71(12.3 \%)$ & 0.046 \\
\hline Arrhythmia & $57(6.2 \%)$ & $24(7.1 \%)$ & $33(5.7 \%)$ & 0.415 \\
\hline Pulmonary disease $^{\mathrm{b}}$ & $66(7.2 \%)$ & $30(8.8 \%)$ & $36(6.3 \%)$ & 0.144 \\
\hline Diabetes & $219(23.9 \%)$ & $84(24.8 \%)$ & $135(23.4 \%)$ & 0.646 \\
\hline Abnormal liver function ${ }^{c}$ & $45(4.9 \%)$ & $19(5.6 \%)$ & $26(4.5 \%)$ & 0.462 \\
\hline Malignant tumor & $105(11.5 \%)$ & $39(11.5 \%)$ & $66(11.5 \%)$ & 0.983 \\
\hline Chronic smoking $^{\mathrm{d}}$ & $223(24.4 \%)$ & $71(20.9 \%)$ & $152(26.4 \%)$ & 0.064 \\
\hline Alcoholism ${ }^{\mathrm{e}}$ & $144(15.7 \%)$ & $45(13.3 \%)$ & $99(17.2 \%)$ & 0.116 \\
\hline Charlson Comorbidity Index ${ }^{\mathrm{f}}$ & $2(2,3)$ & $2(2,3)$ & $2(2,3)$ & 0.580 \\
\hline History of surgery & $491(53.7 \%)$ & $199(58.7 \%)$ & $292(50.7 \%)$ & 0.019 \\
\hline ASA classification & & & & 0.018 \\
\hline Class II & $678(74.0 \%)$ & $236(69.6 \%)$ & $442(76.7 \%)$ & \\
\hline Class III & $237(26.0 \%)$ & $103(31.4 \%)$ & $134(23.3 \%)$ & \\
\hline \multicolumn{5}{|l|}{ Preoperative lab tests } \\
\hline Hematocrit (\%) & $39.4 \pm 5.3$ & $38.5 \pm 5.8$ & $39.9 \pm 4.9$ & $<0.001$ \\
\hline Albumin $(\mathrm{g} / \mathrm{L})$ & $40.6 \pm 4.7$ & $39.9 \pm 4.7$ & $40.9 \pm 4.7$ & 0.002 \\
\hline Creatinine $(\mu \mathrm{mol} / \mathrm{L})$ & $80.2 \pm 20.9$ & $81.0 \pm 21.9$ & $79.7 \pm 20.2$ & 0.354 \\
\hline Glucose $<4.0$ or $>10.0 \mathrm{mmol} / \mathrm{L}$ & $47(5.1 \%)$ & $20(5.9 \%)$ & $27(4.7 \%)$ & 0.423 \\
\hline $\mathrm{Na}^{+}<135.0$ or $>145.0 \mathrm{mmol} / \mathrm{L}$ & $37(4.0 \%)$ & $13(3.8 \%)$ & $24(4.2 \%)$ & 0.802 \\
\hline $\mathrm{K}^{+}<3.5$ or $>5.5 \mathrm{mmol} / \mathrm{L}$ & $117(12.8 \%)$ & $48(14.2 \%)$ & $69(12 \%)$ & 0.346 \\
\hline Preoperative MMSE (score) & $26.3 \pm 2.3$ & $25.5 \pm 2.5$ & $26.7 \pm 2.1$ & $<0.001$ \\
\hline Duration of anesthesia (min) & $279 \pm 77$ & $285 \pm 74$ & $276 \pm 79$ & 0.075 \\
\hline Type of anesthesia & & & & 0.616 \\
\hline General & $420(45.9 \%)$ & $161(47.5 \%)$ & $259(45.0 \%)$ & \\
\hline Peripheral-general & $469(51.3 \%)$ & $167(49.3 \%)$ & $302(52.4 \%)$ & \\
\hline Epidural-general & $26(2.8 \%)$ & $11(3.2 \%)$ & $15(2.6 \%)$ & \\
\hline \multicolumn{5}{|l|}{ Intraoperative medication } \\
\hline Use of nitrous oxide & $553(60.4 \%)$ & $212(62.5 \%)$ & $341(59.2 \%)$ & 0.319 \\
\hline Use of sevoflurane & $287(31.4 \%)$ & $115(33.9 \%)$ & $172(29.9 \%)$ & 0.201 \\
\hline Use of dexmedetomidine & $430(47.0 \%)$ & $164(48.4 \%)$ & $266(46.2 \%)$ & 0.520 \\
\hline Use of midazolam & $189(20.7 \%)$ & $65(19.2 \%)$ & $124(21.5 \%)$ & 0.396 \\
\hline Use of etomidate & $699(76.4 \%)$ & $273(80.5 \%)$ & $426(74.0 \%)$ & 0.024 \\
\hline Propofol (mg) & $840(642,1075)$ & $866(678,1132)$ & $824(622,1050)$ & 0.048 \\
\hline Remifentanil $(\mu \mathrm{g})$ & $726(0,1260)$ & $700(0,1230)$ & $760(0,1299)$ & 0.819 \\
\hline Sufentanil $(\mu \mathrm{g})$ & $40(25,69)$ & $40(25,70)$ & $40(25,68)$ & 0.391 \\
\hline Sufentanil equivalent $(\mu \mathrm{g})$ & $110(77,160)$ & $110(79,156)$ & $110(75,165)$ & 0.853 \\
\hline Rocuronium (mg) & $42.1 \pm 19.0$ & $42.2 \pm 17.8$ & $42.0 \pm 19.7$ & 0.914 \\
\hline NSAIDs $^{g}$ & $726(79.3 \%)$ & $272(80.2 \%)$ & $454(78.8 \%)$ & 0.609 \\
\hline Duration of surgery (min) & $203 \pm 71$ & $208 \pm 67$ & $199 \pm 72$ & 0.078 \\
\hline Type of surgery & & & & 0.001 \\
\hline Thoraco-/laparoscopic & $549(59.9 \%)$ & $179(52.8 \%)$ & $369(64.1 \%)$ & \\
\hline Non thoraco-/laparoscopic & $367(40.1 \%)$ & $160(47.2 \%)$ & $207(35.9 \%)$ & \\
\hline
\end{tabular}


Table 1 (continued)

Total $(n=915)$

Emergence delirium $(n=339)$

No emergence delirium

$P$ value $(n=576)$

\begin{tabular}{|c|c|c|c|c|}
\hline Location of surgery & & & & 0.063 \\
\hline Intra-thoracic & $198(21.6 \%)$ & $61(18.0 \%)$ & $137(23.8 \%)$ & \\
\hline Intra-abdominal & $530(57.9 \%)$ & $199(58.7 \%)$ & $331(57.5 \%)$ & \\
\hline Spinal/extremities/others & $187(20.4 \%)$ & $79(23.3 \%)$ & $108(18.7 \%)$ & \\
\hline Estimated blood loss (ml) & $100(10,250)$ & $100(10,300)$ & $60(10,200)$ & 0.002 \\
\hline Lowest hemoglobin $<10(\mathrm{~g} / \mathrm{dL})$ & $77(8.4 \%)$ & $44(13.0 \%)$ & $33(5.7 \%)$ & $<0.001$ \\
\hline Total fluid infusion (ml) & $2200(1600,2850)$ & $2350(1800,3100)$ & $2100(1600,2600)$ & $<0.001$ \\
\hline Crystalloid (ml) & $1800(1500,2300)$ & $2000(1600,2500)$ & $1700(1300,2300)$ & $<0.001$ \\
\hline Artificial colloid & $530(57.9 \%)$ & $217(64.0 \%)$ & $313(54.3 \%)$ & 0.004 \\
\hline Artificial colloid (ml) & $500(0,500)$ & $500(0,500)$ & $500(0,500)$ & $<0.001$ \\
\hline Autologous blood transfusion & $104(11.4 \%)$ & $48(13.2 \%)$ & $56(9.7 \%)$ & 0.042 \\
\hline Allogeneic blood transfusion & $79(8.6 \%)$ & $43(12.7 \%)$ & $36(6.3 \%)$ & 0.001 \\
\hline Urine output (ml) & $400(250,600)$ & $400(250,700)$ & $400(250,600)$ & 0.072 \\
\hline Emergence agitation & $99(10.8 \%)$ & $73(21.5 \%)$ & $26(4.5 \%)$ & $<0.001$ \\
\hline \multicolumn{5}{|l|}{ Temperature in PACU $\left({ }^{\circ} \mathrm{C}\right)$} \\
\hline At PACU admission & $36.1 \pm 0.4$ & $36.0 \pm 0.4$ & $36.1 \pm 0.4$ & $<0.001$ \\
\hline Temperature $<36^{\circ} \mathrm{C}$ & $301(32.9 \%)$ & $154(45.4 \%)$ & $147(25.5 \%)$ & $<0.001$ \\
\hline \multicolumn{5}{|l|}{ NRS pain score in PACU } \\
\hline First pain score & $2.0(2.0,3.0)$ & $2.0(2.0,4.0)$ & $2.0(1.0,3.0)$ & 0.003 \\
\hline Average pain score & $2.0(1.3,3.0)$ & $2.3(1.7,3.7)$ & $2.0(1.0,3.0)$ & $<0.001$ \\
\hline Patient-controlled analgesia & & & & 0.611 \\
\hline None & $42(4.6 \%)$ & $13(3.8 \%)$ & $29(5.0 \%)$ & \\
\hline Intravenous & $847(92.6 \%)$ & $315(92.9 \%)$ & $532(92.4 \%)$ & \\
\hline Epidural & $26(2.8 \%)$ & $11(3.2 \%)$ & $15(2.6 \%)$ & \\
\hline \multicolumn{5}{|l|}{ Supplemental analgesia in 5 days } \\
\hline Opioids $^{\mathrm{h}}$ & $133(14.5 \%)$ & $55(16.2 \%)$ & $78(13.5 \%)$ & 0.267 \\
\hline NSAIDs $^{\mathrm{i}}$ & $668(73.0 \%)$ & $245(72.3 \%)$ & $423(73.4 \%)$ & 0.701 \\
\hline \multicolumn{5}{|l|}{ NRS pain score in wards } \\
\hline First pain score & $2.0(1.0,3.0)$ & $2.0(1.0,3.0)$ & $2.0(1.0,3.0)$ & 0.785 \\
\hline Average pain score & $1.3(0.3,2.5)$ & $1.2(0.2,2.5)$ & $1.5(0.3,2.5)$ & 0.562 \\
\hline
\end{tabular}

Data are mean $\pm \mathrm{SD}$, number $(\%)$, or median (interquartile range)

$A S A$ American Society of Anesthesiologists, MMSE mini-mental state examination, $P A C U$ post-anesthesia care unit, $N R S$ numeric rating scales, NSAIDs non-steroidal anti-inflammatory drugs

${ }^{a}$ Includes hemorrhagic and ischemic stroke

${ }^{\mathrm{b}}$ Includes chronic obstructive pulmonary disease and asthma

${ }^{c}$ Alanine transaminase and/or aspartate transaminase higher than 5 times the upper normal limit

${ }^{\mathrm{d}}$ Smoking half a pack of cigarettes per day for at least 2 years

${ }^{\mathrm{e}}$ Two drinks or more daily, or weekly consumption of the equivalent of $150 \mathrm{~mL}$ of alcohol

${ }^{\mathrm{f}}$ According to the Charlson Comorbidity Index without age [23]

${ }^{\mathrm{g}}$ Includes parecoxib and flurbiprofen axetil

${ }^{\mathrm{h}}$ Includes morphine, oxycodone, and tramadol

${ }^{\mathrm{i}}$ Includes parecoxib, flurbiprofen axetil, loxoprofen, and celecoxib

risk of POD in the elderly after general anesthesia and major surgery. Furthermore, we found that patients with emergence delirium stayed longer in the PACU and hospital and developed more non-delirium complications within 30 days; which were in line with previous studies $[5,8-10$,
22]. Therefore, delirium monitoring should be performed PACU patients.

The potential mechanisms underlying the association between emergence delirium and POD are not clear. According to previous studies, most of the risk factors of emergence 


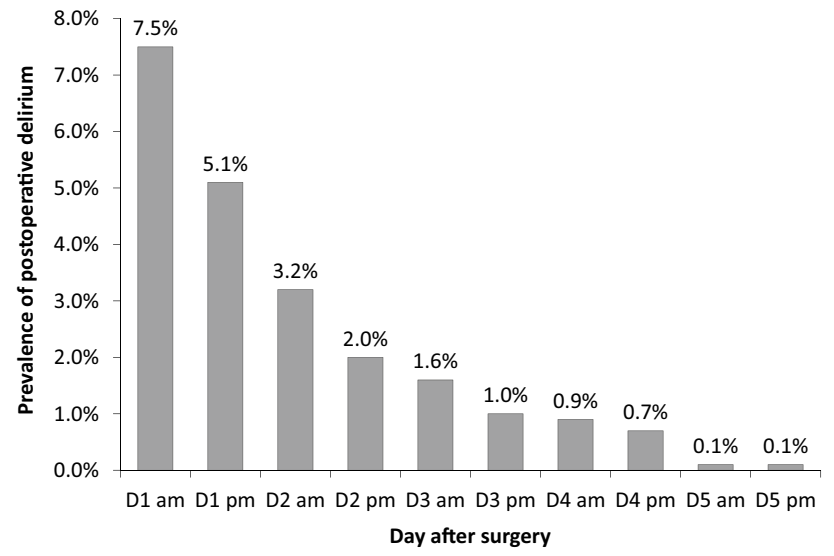

Fig. 3 Prevalence of postoperative delirium

delirium are similar with those of POD. For example, among the identified predictors of emergence delirium, patientrelated factors include old age, pre-existing diseases, substance misuse, cognitive impairment, and psychiatric problems; treatment-related factors include premedication with benzodiazepine, etomidate for induction, EEG burst suppression during anesthesia, major and long-duration surgery, large blood loss, and high pain score after surgery [4-13]. In the present study, old age, low albumin level, poor cognitive function, and high pain score were identified as risk factors of emergence delirium; which were in accord with previous studies [4-13]. And all these factors have been reported to be associated increased odds of POD [16-18]. The existence of common risk factors indicates that emergence delirium may share some similar mechanisms with POD but warrants further study. It is noteworthy that emergence agitation was identified as a risk factor of emergence delirium. As a matter of fact, the two terms have been used interchangeably in previous studies, and the same assessment tool (e.g., RASS or Riker Sedation-Agitation Scale) have been used for both conditions $[4,5,9,10,13,34]$. We also found that hypothermia at the PACU admission was associated with emergence delirium development. A similar result was reported by others for emergence delirium but not POD [5]. The above results suggest that maintaining normothermia during anesthesia, preventing agitation during emergence and providing optimal analgesia may reduce emergence delirium and subsequent postoperative delirium but requires further demonstration. Contrary to some of the previous results [34], we found that male patients developed less emergence delirium; more studies are needed.

The strengths of the present study include a relatively large sample size and strictly assessed delirium. There are some limitations. Firstly, as an observational study, we cannot establish a causal relationship between emergence delirium and POD. The clinical impact of emergence delirium needs to be studied further. Secondly, as a single center

Table 2 Postoperative outcomes

\begin{tabular}{|c|c|c|c|c|c|}
\hline & Total $(n=915)$ & $\begin{array}{l}\text { Emergence } \\
\text { delirium } \\
(n=339)\end{array}$ & $\begin{array}{l}\text { No emergence } \\
\text { delirium } \\
(n=576)\end{array}$ & OR, mean difference or HR $(95 \% \mathrm{CI})^{\mathrm{a}}$ & $P$ value \\
\hline Delirium within 5 days & $104(11.4 \%)$ & $57(16.8 \%)$ & $47(8.2 \%)$ & $\mathrm{OR}=2.275(1.506,3.436)$ & $<0.001$ \\
\hline Length of stay in PACU (min) & $43 \pm 15$ & $45 \pm 16$ & $41 \pm 14$ & Mean $\mathrm{D}=4.1(2.0,6.1)$ & $<0.001$ \\
\hline Length of stay in $\mathrm{PACU} \geq 60 \mathrm{~min}$ & $105(11.5 \%)$ & $51(15.0 \%)$ & $54(9.4 \%)$ & $\mathrm{OR}=1.712(1.137,2.576)$ & 0.010 \\
\hline Non-delirium complications within 5 days & $75(8.2 \%)$ & $35(10.3 \%)$ & $40(6.9 \%)$ & $\mathrm{OR}=1.543(0.959,2.481)$ & 0.074 \\
\hline Non-delirium complications within 30 days & $89(9.7 \%)$ & $43(12.7 \%)$ & $46(8.0 \%)$ & $\mathrm{OR}=3.486(1.296,9.376)$ & 0.013 \\
\hline Length of stay in hospital (day) & $8.0(7.7,8.3)$ & $8.0(7.5,8.5)$ & $7.0(6.6,7.3)$ & $\mathrm{HR}=1.022(1.003,1.041)$ & 0.008 \\
\hline Length of stay in hospital $\leq 5$ (day) & $209(22.8 \%)$ & $63-(18.6 \%)$ & $146(25.3 \%)$ & $\mathrm{OR}=0.672(0.482,0.937)$ & 0.019 \\
\hline Length of stay in hospital $\geq 11$ (day) & $248(27.1 \%)$ & $105(31.0 \%)$ & $143(24.8 \%)$ & $\mathrm{OR}=1.359(1.009,1.830)$ & 0.044 \\
\hline Cognitive function at 30 days (score) ${ }^{b}$ & $34.4 \pm 2.4[16]$ & $34.3 \pm 2.4[7]$ & $34.4 \pm 2.4[9]$ & Mean $\mathrm{D}=0.06(-0.27,0.39)$ & 0.736 \\
\hline \multicolumn{6}{|l|}{ Quality of life at 30 days (score) $)^{\mathrm{c}}$} \\
\hline Social relationships & $82.9 \pm 6.0[16]$ & $82.7 \pm 5.8[7]$ & $83.1 \pm 6.1[9]$ & Mean $\mathrm{D}=0.43(-0.39,1.25)$ & 0.304 \\
\hline Environmental & $78.4 \pm 5.9[16]$ & $78.2 \pm 5.6[7]$ & $78.5 \pm 6.1[9]$ & Mean $\mathrm{D}=0.35(-0.45,1.16)$ & 0.391 \\
\hline Physical & $74.7 \pm 6.1[16]$ & $74.6 \pm 6.3[7]$ & $74.7 \pm 5.9[9]$ & Mean $\mathrm{D}=0.12(-0.71,0.95)$ & 0.780 \\
\hline Psychological & $82.1 \pm 5.6[16]$ & $81.9 \pm 5.7[7]$ & $82.2 \pm 5.5[9]$ & Mean $\mathrm{D}=0.22(-0.54,0.98)$ & 0.565 \\
\hline
\end{tabular}

Data are number $(\%)$, mean $\pm \mathrm{SD}$, or median (95\% confidence interval). Numbers in square brackets indicate patients with missing data $P A C U$ post-anesthesia care unit

${ }^{\text {a }}$ Calculated as emergence delirium vs. or minus no emergence delirium

${ }^{\mathrm{b}}$ Assessed with the Telephone Interview for Cognitive Status-modified; score ranges from 0 to 50, with higher score indicating better function

${ }^{c}$ Assessed with the World Health Organization Quality of Life-brief version; scores range from 0 to 100 in each domain, with higher score indicating better quality of life 
Table 3 Univariate analysis (Logistic regression model)

\begin{tabular}{|c|c|c|c|c|}
\hline & \multicolumn{2}{|l|}{ Postoperative delirium } & \multicolumn{2}{|l|}{ Emergence delirium } \\
\hline & Odds ratio $(95 \% \mathrm{CI})$ & $P$ value & Odds ratio $(95 \% \mathrm{CI})$ & $P$ value \\
\hline Age (years) & $1.071(1.032-1.110)$ & $<0.001$ & $1.077(1.049-1.105)$ & $<0.001$ \\
\hline Male sex & $0.903(0.597-1.365)$ & 0.627 & $0.807(0.614-1.060)$ & 0.124 \\
\hline Body mass index $\left(\mathrm{kg} / \mathrm{m}^{2}\right)$ & $0.944(0.889-1.002)$ & 0.058 & $0.986(0.948-1.025)$ & 0.473 \\
\hline Education (year) & $0.984(0.942-1.028)$ & 0.474 & $0.945(0.917-0.973)$ & $<0.001$ \\
\hline \multicolumn{5}{|l|}{ Preoperative comorbidity } \\
\hline Stroke & $2.514(1.273-4.964)$ & 0.008 & $0.743(0.406-1.360)$ & 0.336 \\
\hline Hypertension & $0.841(0.559-1.265)$ & 0.406 & $0.946(0.723-1.237)$ & 0.683 \\
\hline Coronary heart disease & $1.030(0.576-1.844)$ & 0.919 & $1.468(1.008-2.139)$ & 0.046 \\
\hline Arrhythmia & $1.729(0.846-3.536)$ & 0.133 & $1.254(0.728-2.160)$ & 0.415 \\
\hline Pulmonary disease & $2.043(1.073-3.892)$ & 0.030 & $1.456(0.880-2.411)$ & 0.144 \\
\hline Diabetes & $1.264(0.799-1.999)$ & 0.317 & $1.076(0.787-1.472)$ & 0.646 \\
\hline Abnormal liver function & $2.703(1.325-5.515)$ & 0.006 & $1.256(0.684-2.306)$ & 0.462 \\
\hline Malignant tumor & $1.742(1.000-3.033)$ & 0.050 & $1.005(0.660-1.530)$ & 0.983 \\
\hline Charlson Comorbidity Index (point) & $1.104(1.024-1.190)$ & 0.010 & $1.016(0.961-1.073)$ & 0.580 \\
\hline ASA classification III (vs. II) & $2.065(1.363-3.128)$ & 0.001 & $1.434(1.065-1.930)$ & 0.018 \\
\hline Chronic smoking & $1.164(0.733-1.848)$ & 0.520 & $0.739(0.536-1.018)$ & 0.064 \\
\hline Alcoholism & $0.815(0.450-1.475)$ & 0.499 & $0.737(0.504-1.080)$ & 0.117 \\
\hline History of surgery & $1.439(0.947-2.186)$ & 0.088 & $1.382(1.054-1.813)$ & 0.019 \\
\hline \multicolumn{5}{|l|}{ Preoperative lab tests } \\
\hline Hematocrit (\%) & $0.932(0.898-0.967)$ & $<0.001$ & $0.951(0.927-0.975)$ & $<0.001$ \\
\hline Albumin (g/L) & $0.957(0.919-0.996)$ & 0.030 & $0.956(0.929-0.984)$ & 0.002 \\
\hline Creatinine $(\mu \mathrm{mol} / \mathrm{L})$ & $1.005(0.996-1.014)$ & 0.288 & $1.003(0.997-1.009)$ & 0.354 \\
\hline $\mathrm{Na}^{+}<135.0$ or $>145.0 \mathrm{mmol} / \mathrm{L}$ & $0.686(0.207-2.273)$ & 0.537 & $0.916(0.460-1.823)$ & 0.802 \\
\hline $\mathrm{K}^{+}<3.5$ or $>5.5 \mathrm{mmol} / \mathrm{L}$ & $0.887(0.469-1.675)$ & 0.711 & $1.210(0.814-1.797)$ & 0.346 \\
\hline Preoperative MMSE (score) & $0.858(0.792-0.930)$ & $<0.001$ & $0.791(0.743-0.841)$ & $<0.001$ \\
\hline Duration of anesthesia (min) & $1.004(1.002-1.006)$ & 0.001 & $1.002(1.000-1.003)$ & 0.075 \\
\hline General anesthesia (vs. combined) & $1.519(1.051-2.197)$ & 0.026 & $0.939(0.736-1.200)$ & 0.616 \\
\hline \multicolumn{5}{|l|}{ Intraoperative medication } \\
\hline Use of nitrous oxide & $1.054(0.693-1.602)$ & 0.807 & $1.150(0.873-1.516)$ & 0.319 \\
\hline Use of sevoflurane & $1.071(0.693-1.656)$ & 0.757 & $1.206(0.902-1.607)$ & 0.201 \\
\hline Use of dexmedetomidine & $0.645(0.423-0.981)$ & 0.040 & $1.092(0.835-1.429)$ & 0.520 \\
\hline Use of midazolam & $1.325(0.823-2.133)$ & 0.246 & $0.865(0.618-1.210)$ & 0.396 \\
\hline Use of etomidate & $1.435(0.851-2.421)$ & 0.175 & $1.456(1.050-2.020)$ & 0.024 \\
\hline Propofol (mg) & $1.001(1.000-1.001)$ & 0.039 & $1.000(1.000-1.001)$ & 0.048 \\
\hline Remifentanil $(\mu \mathrm{g})$ & $1.000(1.000-1.000)$ & 0.578 & $1.000(1.000-1.000)$ & 0.819 \\
\hline Sufentanil $(\mu \mathrm{g})$ & $1.007(1.002-1.012)$ & 0.012 & $1.002(0.998-1.006)$ & 0.391 \\
\hline Sufentanil equivalent $(\mu \mathrm{g})$ & $1.001(0.998-1.004)$ & 0.488 & $1.000(0.998-1.002)$ & 0.853 \\
\hline Rocuronium (mg) & $1.011(1.000-1.023)$ & 0.052 & $1.000(0.993-1.007)$ & 0.914 \\
\hline NSAIDs & $1.186(0.702-2.006)$ & 0.524 & $1.091(0.781-1.523)$ & 0.609 \\
\hline Total fluid infusion (ml) & $1.000(1.000-1.000)$ & 0.002 & $1.000(1.000-1.000)$ & $<0.001$ \\
\hline Allogeneic blood transfusion & $1.613(0.856-3.038)$ & 0.139 & $2.179(1.369-3.469)$ & 0.001 \\
\hline Estimated blood loss (ml) & $1.000(1.000-1.001)$ & 0.111 & $1.001(1.000-1.001)$ & 0.002 \\
\hline Lowest intraoperative $\mathrm{Hb}<10 \mathrm{~g} / \mathrm{dL}$ & $2.446(1.366-4.379)$ & 0.003 & $2.454(1.529-3.939)$ & $<0.001$ \\
\hline Duration of surgery (min) & $1.003(1.001-1.006)$ & 0.010 & $1.002(1.000-1.004)$ & 0.078 \\
\hline Thoraco-/laparoscopic surgery & $0.790(0.524-1.192)$ & 0.262 & $1.593(1.213-2.093)$ & 0.001 \\
\hline \multicolumn{5}{|l|}{ Location of surgery } \\
\hline Intra-thoracic & $1.278(0.678-2.407)$ & 0.448 & $1.350(0.952-1.915)$ & 0.092 \\
\hline Intra-abdominal & $1.129(0.654-1.947)$ & 0.663 & $1.643(1.081-2.497)$ & 0.020 \\
\hline Spinal/extremities/others & Ref & & Ref & \\
\hline
\end{tabular}


Table 3 (continued)

\begin{tabular}{|c|c|c|c|c|}
\hline & \multicolumn{2}{|c|}{ Postoperative delirium } & \multicolumn{2}{|l|}{ Emergence delirium } \\
\hline & Odds ratio $(95 \% \mathrm{CI})$ & $P$ value & Odds ratio $(95 \% \mathrm{CI})$ & $P$ value \\
\hline Emergence agitation & $1.478(1.185-1.843)$ & 0.001 & $5.515(4.515-6.737)$ & $<0.001$ \\
\hline Temperature at PACU admission & $0.930(0.585-1.479)$ & 0.760 & $0.437(0.316-0.604)$ & $<0.001$ \\
\hline Temperature $<36^{\circ} \mathrm{C}$ & $0.990(0.640-1.529)$ & 0.963 & $2.429(1.828-3.228)$ & $<0.001$ \\
\hline First NRS pain score in PACU & $0.911(0.802-1.036)$ & 0.157 & $1.129(1.041-1.224)$ & 0.003 \\
\hline Average NRS pain score in PCAU & $0.992(0.866-1.137)$ & 0.912 & $1.255(1.146-1.375)$ & $<0.001$ \\
\hline Use of patient-controlled analgesia & $3.775(1.777-8.021)$ & 0.001 & $1.286(0.780-2.118)$ & 0.324 \\
\hline Supplemental NSAIDs within 5 days & $1.264(0.781-2.046)$ & 0.340 & - & - \\
\hline Supplemental opioids within 5 days & $1.692(0.800-3.580)$ & 0.169 & - & - \\
\hline Emergence delirium & $2.275(1.506-3.436)$ & $<0.001$ & - & - \\
\hline First NRS pain score in wards & $1.412(1.242-1.606)$ & $<0.001$ & - & - \\
\hline Average NRS pain score in wards & $1.534(1.327-1.773)$ & $<0.001$ & - & - \\
\hline Postoperative complications in 5 days & $4.415(2.411-7.124)$ & $<0.001$ & - & - \\
\hline
\end{tabular}

ASA American Society of Anesthesiologists, PACU post-anesthesia care unit, NRS numeric rating scale, NSAIDs non-steroid anti-inflammatory drugs

Table 4 Predictors of postoperative delirium (Logistic regression model)

\begin{tabular}{|c|c|c|c|c|}
\hline \multirow[t]{2}{*}{ Factors } & \multicolumn{2}{|l|}{ Univariable analyses } & \multicolumn{2}{|l|}{ Multivariable analysis $^{\mathrm{a}}$} \\
\hline & Odds ratio $(95 \% \mathrm{CI})$ & $P$ value & Odds ratio $(95 \% \mathrm{CI})$ & $P$ value \\
\hline Emergence delirium & $2.275(1.506-3.436)$ & $<0.001$ & $1.717(1.078-2.735)$ & 0.023 \\
\hline Age (year) & $1.071(1.032-1.110)$ & $<0.001$ & $1.048(1.004-1.093)$ & 0.031 \\
\hline Body mass index $\left(\mathrm{kg} / \mathrm{m}^{2}\right)$ & $0.944(0.889-1.002)$ & 0.058 & $0.965(0.904-1.031)$ & 0.293 \\
\hline Charlson Comorbidity Index (unit) & $1.104(1.024-1.190)$ & 0.010 & $1.058(0.968-1.155)$ & 0.215 \\
\hline History of surgery & $1.439(0.947-2.186)$ & 0.088 & $1.268(0.784-2.049)$ & 0.334 \\
\hline Preoperative hematocrit (\%) & $0.932(0.898-0.967)$ & $<0.001$ & $0.951(0.906-0.998)$ & 0.042 \\
\hline Preoperative albumin (g/L) & $0.957(0.919-0.996)$ & 0.030 & $1.037(0.981-1.096)$ & 0.196 \\
\hline Preoperative MMSE (score) & $0.858(0.792-0.930)$ & $<0.001$ & $0.885(0.809-0.969)$ & 0.008 \\
\hline General anesthesia & $1.519(1.051-2.197)$ & 0.026 & $1.147(0.713-1.845)$ & 0.571 \\
\hline Use of dexmedetomidine & $0.645(0.423-0.981)$ & 0.040 & $0.658(0.413-1.047)$ & 0.077 \\
\hline Use of midazolam & $1.325(0.823-2.133)$ & 0.246 & $1.277(0.751-2.171)$ & 0.367 \\
\hline Use of etomidate & $1.435(0.851-2.421)$ & 0.175 & $1.524(0.849-2.739)$ & 0.158 \\
\hline Allogeneic blood transfusion & $1.613(0.856-3.038)$ & 0.139 & $1.038(0.495-2.176)$ & 0.922 \\
\hline Duration of surgery (min) & $1.003(1.00-1.006)$ & 0.010 & $1.002(0.998-1.005)$ & 0.329 \\
\hline Supplemental opioids within 5 days & $1.692(0.800-3.580)$ & 0.169 & $1.403(0.774-2.542)$ & 0.264 \\
\hline Use of patient-controlled analgesia & $3.775(1.777-8.021)$ & 0.001 & $2.984(1.035-8.608)$ & 0.043 \\
\hline Average NRS pain score in wards & $1.534(1.327-1.773)$ & $<0.001$ & $1.579(1.347-1.852)$ & $<0.001$ \\
\hline Postoperative complications in 5 days & $4.415(2.411-7.124)$ & $<0.001$ & $3.422(1.834-6.384)$ & $<0.001$ \\
\hline
\end{tabular}

MMSE mini-mental status examination, NRS numeric rating scales

${ }^{a}$ Variables with $P<0.20$ in univariable analyses and those that were considered clinically important were included in the multivariable Logistic regression model (Enter). Preoperative comorbidities including stroke, arrhythmia, pulmonary disease, abnormal liver function, malignant tumor, and ASA classification (III vs. II) were excluded due to correlation with Charlson Comorbidity Index. Duration of anesthesia, propofol $(\mathrm{mg})$, sufentanil $(\mu \mathrm{g})$, rocuronium $(\mathrm{mg})$, and total fluid infusion $(\mathrm{ml})$ were excluded due to correlation with duration of surgery. Emergence agitation was excluded due to correlation with emergence delirium. Estimated blood loss (ml) and the lowest intraoperative $\mathrm{Hb}<10 \mathrm{~g} / \mathrm{dL}$ were excluded due to correlation with allogeneic blood transfusion. First NRS pain score in wards was excluded due to correlation with average NRS pain score in the wards. Hosmer-Lemeshow test of the multivariable model: $\chi^{2}=7.116$, $\mathrm{df}=8, P=0.524$ 
Table 5 Predictors of emergence delirium (Logistic regression model)

\begin{tabular}{|c|c|c|c|c|}
\hline \multirow[t]{2}{*}{ Factors } & \multicolumn{2}{|l|}{ Univariate analysis } & \multicolumn{2}{|l|}{ Multivariate analysis $^{\mathrm{a}}$} \\
\hline & Odds ratio $(95 \% \mathrm{CI})$ & $P$ value & Odds ratio $(95 \% \mathrm{CI})$ & $P$ value \\
\hline Age (year) & $1.077(1.049-1.105)$ & $<0.001$ & $1.042(1.003-1.083)$ & 0.037 \\
\hline Male sex & $0.807(0.614-1.060)$ & 0.124 & $0.530(0.332-0.846)$ & 0.008 \\
\hline Education (year) & $0.945(0.917-0.973)$ & $<0.001$ & $0.996(0.952-1.043)$ & 0.872 \\
\hline ASA classification III & $1.434(1.065-1.930)$ & 0.018 & $1.291(0.830-2.006)$ & 0.257 \\
\hline Chronic smoking & $0.739(0.536-1.018)$ & 0.064 & $0.651(0.373-1.137)$ & 0.131 \\
\hline Alcoholism & $0.737(0.504-1.080)$ & 0.117 & $0.929(0.485-1.780)$ & 0.824 \\
\hline History of surgery & $1.382(1.054-1.813)$ & 0.019 & $1.054(0.712-1.559)$ & 0.792 \\
\hline Preoperative hematocrit (\%) & $0.951(0.927-0.975)$ & $<0.001$ & $0.993(0.953-1.036)$ & 0.761 \\
\hline Preoperative albumin (g/L) & $0.956(0.929-0.984)$ & 0.002 & $0.953(0.912-0.997)$ & 0.036 \\
\hline Preoperative MMSE (score) & $0.791(0.743-0.841)$ & $<0.001$ & $0.799(0.727-0.878)$ & $<0.001$ \\
\hline Use of sevoflurane & $1.206(0.902-1.607)$ & 0.201 & $1.009(0.676-1.508)$ & 0.963 \\
\hline Use of etomidate & $1.456(1.050-2.020)$ & 0.024 & $1.263(0.803-1.987)$ & 0.313 \\
\hline Allogeneic blood transfusion & $2.179(1.369-3.469)$ & 0.001 & $1.696(0.867-3.318)$ & 0.123 \\
\hline Duration of surgery (min) & $1.002(1.000-1.004)$ & 0.078 & $1.000(0.997-1.003)$ & 0.949 \\
\hline Emergence agitation & $5.515(4.515-6.737)$ & $<0.001$ & $6.007(4.752-7.595)$ & $<0.001$ \\
\hline Thoraco-/laparoscopic surgery & $1.593(1.213-2.093)$ & 0.001 & $0.807(0.543-1.199)$ & 0.288 \\
\hline Hypothermia at PACU admission ${ }^{\mathrm{b}}$ & $2.429(1.828-3.228)$ & $<0.001$ & $2.672(1.790-3.988)$ & $<0.001$ \\
\hline Average NRS pain score in PACU & $1.255(1.146-1.375)$ & $<0.001$ & $1.309(1.150-1.489)$ & $<0.001$ \\
\hline Use of patient-controlled analgesia & $1.286(0.780-2.118)$ & 0.324 & $0.946(0.455-1.969)$ & 0.882 \\
\hline
\end{tabular}

MMSE mini-mental status examination, $P A C U$ post-anesthesia care unit

${ }^{a}$ Variables with $P<0.20$ in univariable analyses and those that were considered clinically important were included in the multivariable Logistic regression model (Enter). Preoperative comorbidities including coronary heart disease and pulmonary disease were excluded due to correlation with ASA classification (III vs. II). Duration of anesthesia, propofol $(\mathrm{mg})$ and total fluid infusion $(\mathrm{ml})$ were excluded due to correlation with duration of surgery. Estimated blood loss $(\mathrm{ml})$ and lowest intraoperative $\mathrm{Hb}<10 \mathrm{~g} / \mathrm{dL}$ were excluded due to correlation with allogeneic blood transfusion. Temperature at PACU admission was excluded due to correlation with temperature at PACU admission $<36{ }^{\circ} \mathrm{C}$. First NRS pain score in PACU was excluded due to correlation with average NRS pain score in PACU. Hosmer-Lemeshow test of the multivariable model: $\chi^{2}=17.990, \mathrm{df}=8, \mathrm{P}=0.021$

${ }^{\mathrm{b}}$ Tympanic temperature $<36^{\circ} \mathrm{C}$ at $\mathrm{PACU}$ admission study, the generalizability of our results may be limited. Thirdly, whether emergence delirium is associated with worse long-term outcomes remains unclear and requires further study.

\section{Conclusions}

Our results showed that, in elderly patients admitted to the PACU after general anesthesia and major surgery, emergence delirium is common and is independently associated with an increased risk of postoperative delirium. Patients with emergence delirium have worse perioperative outcomes. Whether measures effective in preventing emergence delirium can reduce postoperative delirium and improve perioperative outcome need to be studied further.

Acknowledgment The authors gratefully acknowledge professor XinYu Sun (Department of Psychiatrics, Peking University Sixth Hospital,
Beijing, China) for her help in psychiatric consultation and personnel training and Professor Daqing Ma (Imperial College London, London, UK) for his critical comments during manuscript preparation.

Author contributions Dong-Xin Wang and Bin Nie contributed to the study conception and design. Yan Zhang, Shu-Ting He and Bin Nie performed material preparation, data collection and analysis. Xue-Ying $\mathrm{Li}$ contributed to the statistical analysis. Yan Zhang drafted the first version manuscript. Dong-Xin Wang and Shu-Ting He critically revised the manuscript. All authors read and approved the final manuscript.

Funding This work was supported by the National Key R\&D Program of China [Grant Numbers 2018YFC2001800] and a Scientific Research Seed Fund [Grant Numbers 2019SF23] from Peking University First Hospital. The sponsors have no role in the study design and conduct; the collection, management, analysis, and interpretation of the data; or the preparation and approval of the manuscript.

\section{Compliance with ethical standards}

Conflict of interest The authors declare no conflict of interests. 
Open Access This article is licensed under a Creative Commons Attribution 4.0 International License, which permits use, sharing, adaptation, distribution and reproduction in any medium or format, as long as you give appropriate credit to the original author(s) and the source, provide a link to the Creative Commons licence, and indicate if changes were made. The images or other third party material in this article are included in the article's Creative Commons licence, unless indicated otherwise in a credit line to the material. If material is not included in the article's Creative Commons licence and your intended use is not permitted by statutory regulation or exceeds the permitted use, you will need to obtain permission directly from the copyright holder. To view a copy of this licence, visit http://creativecommons.org/licenses/by/4.0/.

\section{References}

1. Marcantonio ER. Delirium in hospitalized older adults. N Engl J Med. 2017;377:1456-66.

2. Silverstein JH, Timberger M, Reich DL, Uysal S. Central nervous system dysfunction after noncardiac surgery and anesthesia in the elderly. Anesthesiology. 2007;106:622-8.

3. Evered L, Silbert B, Knopman DS, Scott DA, DeKosky ST, Rasmussen LS, Oh ES, Crosby G, Berger M, Eckenhoff RG, Nomenclature Consensus Working G. Recommendations for the nomenclature of cognitive change associated with anaesthesia and surgery-2018. Br J Anaesth. 2018;121:1005-12.

4. Radtke FM, Franck M, Hagemann L. Risk factors for inadequate emergence after anesthesia: emergence delirium and hypoactive emergence. Minerva Anestesiol. 2010;76:394-403.

5. Xará D, Silva A, Mendonca J, Abelha F. Inadequate emergence after anesthesia: emergence delirium and hypoactive emergence in the Postanesthesia Care Unit. J Clin Anesth. 2013;25:439-46.

6. Card E, Pandharipande P, Tomes C, Lee C, Wood J, Nelson D, Graves A, Shintani A, Ely EW, Hughes C. Emergence from general anaesthesia and evolution of delirium signs in the postanaesthesia care unit. Br J Anaesth. 2015;115:411-7.

7. Kim HC, Kim E, Jeon YT, Hwang JW, Lim YJ, Seo JH, Park HP. Postanaesthetic emergence agitation in adult patients after general anaesthesia for urological surgery. J Int Med Res. 2015;43:226-35.

8. Hesse S, Kreuzer M, Hight D, Gaskell A, Devari P, Singh D, Taylor NB, Whalin MK, Lee S, Sleigh JW, Garcia PS. Association of electroencephalogram trajectories during emergence from anaesthesia with delirium in the postanaesthesia care unit: an early sign of postoperative complications. Br J Anaesth. 2019;122:622-34.

9. Lepouse C, Lautner CA, Liu L, Gomis P, Leon A. Emergence delirium in adults in the post-anaesthesia care unit. Br J Anaesth. 2006:96:747-53

10. Munk L, Andersen G, Moller AM. Post-anaesthetic emergence delirium in adults: incidence, predictors and consequences. Acta Anaesthesiol Scand. 2016;60:1059-66.

11. Wiinholdt D, Eriksen SAN, Harms LB, Dahl JB, Meyhoff CS. Inadequate emergence after non-cardiac surgery-A prospective observational study in 1000 patients. Acta Anaesthesiol Scand. 2019;63:1137-42.

12. Ramroop R, Hariharan S, Chen D. Emergence delirium following sevoflurane anesthesia in adults: prospective observational study. Rev Bras Anestesiol. 2019;69:233-41.

13. Assefa S, Sahile W. Assessment of Magnitude and Associated Factors of Emergence Delirium in the Post Anesthesia Care Unit at Tikur Anbesa Specialized Hospital Ethiopia. Ethiopian J Health Sci. 2019;29:597-604.

14. Sharma PT, Sieber FE, Zakriya KJ, Pauldine RW, Gerold $\mathrm{KB}$, Hang J, Smith TH. Recovery room delirium predicts postoperative delirium after hip-fracture repair. Anesth Analg. 2005;101:1215-20.

15. Neufeld KJ, Leoutsakos JM, Sieber FE, Wanamaker BL, Gibson Chambers JJ, Rao V, Schretlen DJ, Needham DM. Outcomes of early delirium diagnosis after general anesthesia in the elderly. Anesth Analg. 2013;117:471-8.

16. Razak HRBA, Yung WY. Postoperative delirium in patients undergoing total joint arthroplasty: a systematic review. J Arthroplasty. 2015;30:1414-7.

17. Zhu C, Wang B, Yin J, Xue Q, Gao S, Xing L, Wang H, Liu W, Liu X. Risk factors for postoperative delirium after spinal surgery: a systematic review and meta-analysis. Aging Clin Exp Res. 2019. https://doi.org/10.1007/s40520-019-01319-y.

18. Lee SH, Lim SW. Risk factors for postoperative delirium after colorectal surgery: a systematic review and meta-analysis. Int J Colorectal Dis. 2020. https://doi.org/10.1007/s00384-019-03498 $-6$.

19. Aitken SJ, Blyth FM, Naganathan V. Incidence, prognostic factors and impact of postoperative delirium after major vascular surgery: a meta-analysis and systematic review. Vasc Med. 2017;22:387-97.

20. Brown CH, LaFlam A, Max L, Wyrobek J, Neufeld KJ, Kebaish KM, Cohen DB, Walston JD, Hogue CW, Riley LH. Delirium after spine surgery in older adults: incidence, risk factors, and outcomes. J Am Geriatr Soc. 2016;64:2101-8.

21. Gleason LJ, Schmitt EM, Kosar CM, Tabloski P, Saczynski JS, Robinson T, Cooper Z, Rogers SO Jr, Jones RN, Marcantonio ER, Inouye SK. Effect of delirium and other major complications on outcomes after elective surgery in older adults. JAMA Surg. 2015;150:1134-40.

22. Fields A, Huang J, Schroeder D, Sprung J, Weingarten T. Agitation in adults in the post-anaesthesia care unit after general anaesthesia. Br J Anaesth. 2018;121:1052-8.

23. Charlson ME, Pompei P, Ales KL, MacKenzie CR. A new method of classifying prognostic comorbidity in longitudinal studies: development and validation. J Chronic Dis. 1987;40:373-83.

24. Sessler CN, Gosnell MS, Grap MJ, Brophy GM, O’Neal PV, Keane KA, Tesoro EP, Elswick RK. The Richmond AgitationSedation Scale: validity and reliability in adult intensive care unit patients. Am J Respir Crit Care Med. 2002;166:1338-44.

25. Inouye $\mathrm{SK}$, vanDyck $\mathrm{CH}$, Alessi $\mathrm{CA}$, Balkin $\mathrm{S}$, Siegal AP, Horwitz RI. Clarifying confusion: The confusion assessment method. A new method for detection of delirium. Annals Internal Med. 1990;113:941-8.

26. Ely EW, Margolin R, Francis J, May L. Evaluation of delirium in critically ill patients: validation of the confusion assessment method for the intensive care unit (CAM-ICU). Crit Care Med. 2001;29:1370-9.

27. Su X, Meng Z-T, Wu X-H, Cui F, Li H-L, Wang D-X, Zhu X, Zhu S-N, Maze M, Ma D. Dexmedetomidine for prevention of delirium in elderly patients after non-cardiac surgery: a randomised, double-blind, placebo-controlled trial. Lancet. 2016;388:1893-902.

28. Li CJ, Wang BJ, Mu DL, Hu J, Guo C, Li XY, Ma D, Wang DX. Randomized clinical trial of intraoperative dexmedetomidine to prevent delirium in the elderly undergoing major non-cardiac surgery. Br J Surg. 2020;107:e123-32.

29. Peterson JF, Pun BT, Dittus RS, Thomason JW, Jackson JC, Shintani AK, Ely EW. Delirium and its motoric subtypes: a study of 614 critically ill patients. J Am Geriatr Soc. 2006;54:479-84.

30. Dindo D, Demartines N, Clavien PA. Classification of surgical complications: a new proposal with evaluation in a cohort of 6336 patients and results of a survey. Ann Surg. 2004;240:205-13.

31. Khwaja A. KDIGO clinical practice guidelines for acute kidney injury. Nephron Clin Pract. 2012;120:179-84. 
32. Hao YT, Fang JQ, Power MJ, Wu SM, Zhu SM. The Equivalence of WHOQOL-BREF among 13 culture versions. Zhong Guo Xin Li Wei Sheng Za Zhi. 2006;20:71-5.

33. Meng C, Zhang XQ, Bi ZY, Wei GZ, Zhou JS, Wang H, Sun HL. Telephone interview for cognitive status-modified used in screening cognitive impairment. Zhong Hua Shen Jing Ke Za Zhi. 2005; 1:30-3.

34. Lee SJ, Sun TY. Emergence agitation: current knowledge and unresolved questions. Korean J Anesthesiol. 2020. https://doi. org/10.4097/kja.20097.
Publisher's Note Springer Nature remains neutral with regard to jurisdictional claims in published maps and institutional affiliations. 